\title{
Association of the Promoter Haplotype of IFN- $\gamma$-Inducible Protein 16 Gene with Schizophrenia in a Korean Population
}

\author{
Won Sub Kang ${ }^{1}$, Su Kang Kim², and Hae Jeong Park ${ }^{3 凶}$ \\ ${ }^{1}$ Department of Neuropsychiatry, School of Medicine, Kyung Hee University, Seoul, Republic of Korea \\ ${ }^{2}$ Department of Biomedical Laboratory Science, Catholic Kwandong University, Gangneung, Republic of Korea \\ ${ }^{3}$ Department of Pharmacology, School of Medicine, Kyung Hee University, Seoul, Republic of Korea
}

\begin{abstract}
Objective Viral infections play an important role in the development of schizophrenia, inducing the faulty immunological responses and aberrant inflammation. IFN- $\gamma$-inducible protein 16 (IFI16) is an immunological DNA sensor against viral infections, triggering the inflammatory responses. In this study, we investigated an association between putative promoter single nucleotide polymorphisms (SNPs) and haplotypes of IFI16 and schizophrenia.

Methods A total of 280 schizophrenia patients and 427 control subjects were recruited in this study. We genotyped three promoter SNPs (rs1465175, rs3754464, rs1417806) using direct sequencing. Associations of SNPs and haplotypes of IFI16 with schizophrenia were analyzed. The promoter activities on the haplotypes of IFI16 were measured.

Results The $\mathrm{T}$ allele of rs1465175 and the $\mathrm{C}$ allele of rs1417806 were protectively associated with schizophrenia ( $\mathrm{p}=0.021$ on rs 1465175 ; $\mathrm{p}=0.016$ on rs1417806), whereas the $\mathrm{G}$ allele of rs3754464 was associated with an increased risk of schizophrenia ( $\mathrm{p}=0.019)$. In haplotype analysis, a significant association between the GGA haplotype and schizophrenia was shown ( $\mathrm{p}=0.013)$. Moreover, we found that the GGA haplotype elevated the promoter activity compared to the GAA haplotype, whereas the TAC haplotype reduced that.

Conclusion The promoter SNPs and haplotypes of IFI16 may contribute to the susceptibility of schizophrenia, affecting the promoter activity of IFI16.

Psychiatry Investig 2020;17(2):140-146
\end{abstract}

Key Words Schizophrenia, IFN- $\gamma$-inducible protein 16, Single nucleotide polymorphisms, Promoter activity.

\section{INTRODUCTION}

Schizophrenia is a severe neuropsychiatric disorder of variable psychopathology with a lifetime prevalence of approximately $1 \%$ worldwide. Recently, viral hypothesis of schizophrenia suggests that viral infections may be implicated in an increased risk of schizophrenia. ${ }^{1-3}$ In particular, the involvement of Herpes viruse-1 (HSV-1) infection in schizophrenia has been suggested. In not only patients with schizophrenia ${ }^{4,5}$ but also the general population, ${ }^{6}$ the HSV-1 antibody prevalence was approximately $40 \%$ to $60 \%$. HSV-1 infection causes no or mild symptoms in most individuals. However, HSV-1 is

Received: July 10, 2019 Revised: November 7, 2019

Accepted: November 18, 2019

$\triangle$ Correspondence: Hae Jeong Park, PhD

Department of Pharmacology, School of Medicine, Kyung Hee University, 26 Kyungheedae-ro, Dongdaemun-gu, Seoul 02447, Republic of Korea Tel: +82-2-961-9547, E-mail: hjpark17@khu.ac.kr

(a) This is an Open Access article distributed under the terms of the Creative Commons Attribution Non-Commercial License (https://creativecommons.org/licenses/bync/4.0) which permits unrestricted non-commercial use, distribution, and reproduction in any medium, provided the original work is properly cited. also the most common causes of sporadic encephalitis along with psychosis and cognitive impairment. ${ }^{7.8} \mathrm{~A}$ lot of studies have reported the significant relationships between HSV-1 seropositive status and schizophrenia and its clinical symptoms, especially cognitive impairment. ${ }^{4,9-12}$ Viral infections trigger a response from both the innate and adaptive immune systems. Thus, the abnormal persistent inflammatory responses by viral infection and reactivation may lead to the alteration of cortical circuits in the brain and the symptoms of schizophrenia including cognitive impairment. ${ }^{1-3}$ Indeed, previous studies have reported evidences on the contribution of the immunological abnormalities to schizophrenia, ${ }^{13,14}$ including the genetic associations between schizophrenia risk and HLA and TLR genes. ${ }^{15-17}$

The recognition of DNA into the cell is an essential strategy employed by host immune cells against viral pathogens, leading to stimulation of the inflammasome and type I interferon (IFN) pathways. ${ }^{18}$ Invading DNA is detected by absent in melanoma (AIM)-like receptors (ALRs) together with DNA-dependent activator of interferon-regulatory factors 
(DAI) and cyclic GMP-AMP (cGAMP) synthase (cGAS). IFI16 is a member of ALR family as well as of the PYHIN protein family that contain an N-terminal PYRIN domain and a C-terminal HIN (haemopoietic expression, interferoninducibility, nuclear localization) domain..$^{19}$ IFI16 has been shown to bind DNA directly via its HIN domain, eventually producing antiviral and proinflammatory cytokines. Moreover, IFI16 can form inflammasome complexes, which resulted in activations of caspase- 1 and interleukin- $1 \beta{ }^{20,21} \mathrm{In}$ deed, IFI16 was reported to induce the inflammasome in response to Kaposi Sarcoma-associated herpesvirus infection acting as a nuclear pathogen sensor. ${ }^{22}$ In addition, a genetic study reported that single nucleotide polymorphism (SNP) of IFI16 (rs22776404) was associated with the resistance to genital herpes, correlating with IFI16 expression levels and herpes simplex virus-2 (HSV-2)-induced INF- $\beta$ expression. ${ }^{23}$ In PBMCs from individuals with protective IFI16 haplotype (comprised of the $\mathrm{G}$ allele of rs22776404) against genital herpes, higher level of IFI16 mRNA was revealed, and also IFN- $\beta$ expression was elevated after HSV- 2 infection. ${ }^{23}$ These results indicated that IFI16 may elevate an immune response and thus defenses against virus infection.

Given previous reports, we postulated that IFI16 might be involved in the development of schizophrenia, affecting the detection ability against viral DNA and immunological/inflammatory responses in viral infection and reactivation. However, to our knowledge, no study has explored the genetic association between IFI16 and schizophrenia. In this study, we investigated the association between polymorphisms within putative promoter region of IFI16 and schizophrenia in a Korean population. In addition, we measured the effect of the polymorphisms on the promoter activity.

\section{METHODS}

\section{Subjects}

Four hundred twenty-seven healthy control subjects (190 males and 237 females; mean age \pm standard deviation= $49.1 \pm 11.0$ years) and 280 schizophrenia patients ( 173 males and 107 females; $46.1 \pm 10.5$ years) with Korean background were participated in this study. All patients were recruited from Kyung Hee Medical Center in Seoul, Republic of Korea and were diagnosed as schizophrenia by psychiatrists according to the Diagnostic and Statistical Manual of Mental Disorders, 5th Edition (DSM-5). Based on review of hospital records and personal interviews, patients were also rated using the Operational Criteria (OPCRIT) checklist. ${ }^{24}$ Based on the OPCRIT checklist, schizophrenia patients with symptoms of 54-65 items were categorized as patients with delusion. The patients with symptoms 73-77 items were categorized as patients with hallucination.
Most of schizophrenia patients have delusion and hallucination. Table 1 showed a clinical characteristics of schizophrenia patients. Control subjects were recruited from subjects who visited the hospital for routine health checkups. Only unaffected subjects without psychiatric disturbances and a family history of psychiatric disorders were included in this study. All subjects provided informed consent before the study. The study protocol was approved by the ethics review committee of the Medical Research Institute, Kyung Hee University Medical Center, Seoul, Republic of Korea (KHNMC GRRB 2011-009).

\section{SNP selection and genotyping}

We selected SNPs located in the putative promoter region within -1000 bp from the transcriptional start sites of IFI16 gene at the National Center for Biotechnology Information SNP database (http://www.ncbi.nlm.nih.gov/SNP, BUILD 152). SNPs with a minor allele frequency of $\geq 0.05$ in Chinese and Japanese populations were sorted for this study (Supplementary Table 1 in the online-only Data Supplement). Finally, three SNPs [rs1465175 (-760G/T), rs3754464 (-746A/G), rs1417806 (-491A/C)] were selected.

Genomic DNA of each subject was isolated from the whole blood using the High Pure PCR Template Preparation kit (Roche, Mannheim, Germany). PCR product (381 bp) including rs1465175, rs3754464 and rs1417806 was amplified using extracted genomic DNA and the specific primers (sense, 5'-CCGGAAGTTCAGTGCATTTT-3'; antisense, 5'-AGTGGCAGGAGGAGATCTTG-3'). SNPs were genotyped via direct sequencing using the ABI PRISM 3730XL analyzer (PE Applied Biosystems, Foster City, CA, USA).

\section{Transfection and luciferase activity assay}

In order to assess the effect of the haplotypes on the promoter activity of IFI16, we made constructs on the GAA, GGA, and TAC haplotypes that were the common haplotypes showing the frequencies $\geq 0.05$ in our studied population $(0.58$,

Table 1. Clinical characteristics of the schizophrenia patients

\begin{tabular}{|c|c|c|}
\hline & Schizophrenia & Control \\
\hline & $(\mathrm{N}=280)$ & $(\mathrm{N}=427)$ \\
\hline Male/female (N) & $173 / 107$ & $190 / 237$ \\
\hline \multicolumn{3}{|l|}{ Age (mean age $\pm S D$, years) } \\
\hline Male & $46.2 \pm 10.4$ & $49.3 \pm 11.4$ \\
\hline Female & $46.0 \pm 10.8$ & $49.0 \pm 10.7$ \\
\hline Delusion (absent/present) & $40 / 240$ & \\
\hline Hallucination (absent/present) & $129 / 151$ & \\
\hline
\end{tabular}

Delusion indicates those schizophrenia patients with symptoms of 54-65 items on the Operational Criteria (OPCRIT) checklist. Hallucination indicates schizophrenia patients with symptoms 73-77 items of the OPCRIT checklist 
0.19 , and 0.17 , respectively). The $381 \mathrm{bp}$ fragment in the 5 -upstream region of the human IFI16 including rs1465175, rs3754464 and rs1417806 was prepared by PCR using human genomic DNA purchased from Promega (Madison, WI, USA). The PCR product was cloned and sequenced. We confirmed major allele homozygote genotypes on all of rs1465175, rs3754464, and rs1417806 from the PCR product (the GAA haplotype). The GGA, and TAC haplotype plasmids were produced through point mutation from the GAA haplotype plasmid using Phusion site-directed mutagenesis kit (Thermo Fisher Scientific, Seoul, Republic of Korea) according to the manufacturer's protocol. The GAA, GGA, and TAC haplotype inserts were sucloned using $K p n \mathrm{I}$ and $\mathrm{XhoI}$ sites upstream of the pGL3-basic luciferase reporter vector (Promega).

Human neuroblastoma SH-SY5Y cells were seeded in 24well plates at the density of $1 \times 10^{5}$ per well and incubated overnight in Dulbecco's modified Eagle's medium supplemented with $10 \%$ fetal bovine serum, 50 units $/ \mathrm{mL}$ of penicillin, and $50 \mu \mathrm{g} / \mathrm{mL}$ streptomycin. Cells were transfected with $490 \mathrm{ng}$ of the reporter construct and $10 \mathrm{ng}$ of pRL-TK vector, which provides constitutive expression of Renilla luciferase, using Lipofectamine LTX (Thermo Fisher Scientific). Transfected cells were incubated for $48 \mathrm{~h}$, and then were lysed for luciferase activity assay. Luciferase activity was assessed by the Dual-Luciferase Reporter Assay System (Promega) using the TD 20/20 Luminometer (Turner Design, Sunnyvale, CA, USA). The value for firefly luciferase activity was normalized to the value for Renilla luciferase activity. Assays were conducted in triplicate in three independent experiments.

\section{Statistical analyses}

SNPStats (http://bioinfo.iconcologia.net/index.php) and SPSS 18.0 software were used for analyzing the Hardy-Weinberg equilibrium (HWE) and the genetic data. In order to assess the associations between the genotypes of SNPs and schizophrenia, the odds ratios (ORs) and their 95\% confidence intervals (CIs) were calculated with logistic regression analyses, controlling age and sex as covariables. In the logistic regression analysis for each SNP, models assuming additive inheritances, dominant inheritance, and recessive inheritance were used. False discovery rate (FDR) adjustment was applied for multiple testing correction. The power calculation for the association test and samples was performed using a genetic power calculator (http://zzz.bwh.harvard.edu/gpc/). Employing the genotype relative risk and high risk allele frequency for each SNP, the sample power was calculated and the number of effective sample for power more than 0.8 was determined ( $\alpha=0.05$ ). Linkage disequilibrium (LD) and association between haplotypes consisting of three SNPs and schizophrenia were also analyzed using SNPStats.
Data on luciferase activity are reported as mean \pm SE. Levels of significance were analyzed by one-way analysis of variance (ANOVA) with Tukey's HSD post hoc test.

In all statistical analyses, a p-value less than 0.05 was considered significant.

\section{RESULTS}

Three promoter SNPs of IFI16 were polymorphic, and the genotype distributions of the SNPs were in HWE ( $p>0.05$; data not shown). As shown in Table 2, we found significant associations between the promoter SNPs of IFI16 and schizophrenia. rs1465175 of IFI16 was associated with schizophrenia in the additive (G/G vs. G/T vs. T/T, $\mathrm{p}=0.019$, OR=0.71, $95 \% \mathrm{CI}=0.53-0.95)$ and recessive models $(\mathrm{G} / \mathrm{G}-\mathrm{G} / \mathrm{T}$ vs. $\mathrm{T} / \mathrm{T}$, $\mathrm{p}=0.013, \mathrm{OR}=0.21,95 \% \mathrm{CI}=0.06-0.75)$. The frequencies of the $\mathrm{G} / \mathrm{G}, \mathrm{G} / \mathrm{T}$ and $\mathrm{T} / \mathrm{T}$ genotypes were $61.6 \%, 33.8 \%$, and $4.6 \%$ in control subjects, and $68.5 \%, 30.5 \%$, and $1.1 \%$ in schizophrenia patients. In addition, in allele frequency analysis, a significant association was detected $(\mathrm{p}=0.021, \mathrm{OR}=0.71$, 95\% CI=0.54-0.94). The frequency of the $\mathrm{T}$ allele was lower in schizophrenia patients $(16.3 \%)$ than in control subjects (21.5\%). This result indicated that the TT genotype and the T allele were associated with a decreased risk of schizophrenia.

We also found an association between rs3754464 and schizophrenia. In the additive model (A/A vs. A/G vs. G/G), the genotype distributions of rs3754464 were significantly different between the schizophrenia patients and control subjects ( $\mathrm{p}=0.019, \mathrm{OR}=1.41,95 \% \mathrm{CI}=1.08-1.86$ ). Additionally, in the dominant model (A/A vs. A/G-G/G), rs3754464 was significantly association with schizophrenia $(\mathrm{p}=0.036, \mathrm{OR}=1.45$, 95\% CI=1.05-2.00). The frequencies of the $A / G$ and $G / G$ genotypes were $28.8 \%$ and $3.2 \%$ in the control subjects, and $36.0 \%$ and $5.8 \%$ in the schizophrenia patients, respectively. Allele frequency analysis also revealed a significant association of the $\mathrm{G}$ allele with schizophrenia $(\mathrm{p}=0.019, \mathrm{OR}=1.45$, 95\% CI=1.11-1.88). The frequency of the $\mathrm{G}$ allele was increased in schizophrenia patients $(23.3 \%)$, compare to control subjects $(17.7 \%)$.

Moreover, rs1417806 showed the significant associations in the additive (A/A vs. $\mathrm{C} / \mathrm{A}$ vs. $\mathrm{C} / \mathrm{C}, \mathrm{p}=0.017, \mathrm{OR}=0.73,95 \%$ $\mathrm{CI}=0.55-0.96)$ and recessive models $(\mathrm{A} / \mathrm{A}-\mathrm{C} / \mathrm{A}$ vs. $\mathrm{C} / \mathrm{C}$, $\mathrm{p}=0.010, \mathrm{OR}=0.35,95 \% \mathrm{CI}=0.14-0.87)$. The frequency of the $\mathrm{C} / \mathrm{C}$ genotype not containing A allele was significantly reduced in schizophrenia patients The frequencies of the $\mathrm{C} / \mathrm{C}$ genotype were $6.3 \%$ and $2.1 \%$ in the control subjects and the schizophrenia patients, respectively. In allele frequency analysis, the significant association was observed $(p=0.016$, $\mathrm{OR}=0.72,95 \% \mathrm{CI}=0.55-0.94)$. The frequency of the $\mathrm{C}$ allele was lower in schizophrenia patients $(18.1 \%)$ than in control 
Table 2. Multiple logistic regression analysis of promoter single-nucleotide polymorphisms of IFI16 in schizophrenia patients and control subjects

\begin{tabular}{|c|c|c|c|c|c|c|c|}
\hline \multirow{2}{*}{ SNP } & \multirow{2}{*}{ Model } & \multirow{2}{*}{ Genotype/allele } & Con & SCZ & \multirow{2}{*}{ OR (95\% CI) } & \multirow{2}{*}{$\mathrm{p}$-value } & \multirow{2}{*}{$\begin{array}{l}\text { Adjusted } \\
\text { p-value }\end{array}$} \\
\hline & & & $\mathrm{N}(\%)$ & $\mathrm{N}(\%)$ & & & \\
\hline rs1465175 & Additive & G/G & $253(61.6)$ & $191(68.5)$ & 1 & & \\
\hline \multirow[t]{8}{*}{$-760 \mathrm{G} / \mathrm{T}$} & & $\mathrm{G} / \mathrm{T}$ & $139(33.8)$ & $85(30.5)$ & & & \\
\hline & & $\mathrm{T} / \mathrm{T}$ & $19(4.6)$ & $3(1.1)$ & $0.71(0.53-0.95)$ & 0.018 & 0.019 \\
\hline & Dominant & $\mathrm{G} / \mathrm{G}$ & $253(61.6)$ & $191(68.5)$ & 1 & & \\
\hline & & G/T-T/T & $158(38.4)$ & $88(31.5)$ & $0.75(0.54-1.04)$ & 0.083 & 0.093 \\
\hline & Recessive & G/G-G/T & $392(95.4)$ & $276(98.9)$ & 1 & & \\
\hline & & $\mathrm{T} / \mathrm{T}$ & $19(4.6)$ & $3(1.1)$ & $0.21(0.06-0.75)$ & 0.005 & 0.013 \\
\hline & Allele & G & $670(78.5)$ & $467(83.7)$ & 1 & & \\
\hline & & $\mathrm{T}$ & $184(21.5)$ & $91(16.3)$ & $0.71(0.54-0.94)$ & 0.015 & 0.021 \\
\hline rs3754464 & Additive & $\mathrm{A} / \mathrm{A}$ & $279(68.0)$ & $162(58.3)$ & 1 & & \\
\hline \multirow[t]{8}{*}{$-746 \mathrm{~A} / \mathrm{G}$} & & $\mathrm{A} / \mathrm{G}$ & $118(28.8)$ & $100(36.0)$ & & & \\
\hline & & $\mathrm{G} / \mathrm{G}$ & $13(3.2)$ & $16(5.8)$ & $1.41(1.08-1.86)$ & 0.013 & 0.019 \\
\hline & Dominant & $\mathrm{A} / \mathrm{A}$ & $279(68.0)$ & $162(58.3)$ & 1 & & \\
\hline & & A/G-G/G & $131(32.0)$ & $116(41.7)$ & $1.45(1.05-2.00)$ & 0.025 & 0.036 \\
\hline & Recessive & $\mathrm{A} / \mathrm{A}-\mathrm{A} / \mathrm{G}$ & 397 (96.8) & $262(94.2)$ & 1 & & \\
\hline & & $\mathrm{G} / \mathrm{G}$ & $13(3.2)$ & $16(5.8)$ & $1.95(0.90-4.22)$ & 0.082 & 0.082 \\
\hline & Allele & A & $701(82.3)$ & $424(76.7)$ & 1 & & \\
\hline & & G & $151(17.7)$ & $132(23.3)$ & $1.45(1.11-1.88)$ & 0.006 & 0.019 \\
\hline rs1417806 & Additive & $\mathrm{A} / \mathrm{A}$ & $245(59.6)$ & $184(66.0)$ & 1 & & \\
\hline \multirow[t]{8}{*}{$-491 \mathrm{~A} / \mathrm{C}$} & & $\mathrm{C} / \mathrm{A}$ & $140(34.1)$ & 89 (31.9) & & & \\
\hline & & $\mathrm{C} / \mathrm{C}$ & $26(6.3)$ & $6(2.1)$ & $0.73(0.55-0.96)$ & 0.017 & 0.017 \\
\hline & Dominant & $\mathrm{A} / \mathrm{A}$ & $245(59.6)$ & $184(66.0)$ & 1 & & \\
\hline & & $\mathrm{C} / \mathrm{A}-\mathrm{C} / \mathrm{C}$ & $166(40.4)$ & $95(34.0)$ & $0.76(0.55-1.05)$ & 0.083 & 0.083 \\
\hline & Recessive & $\mathrm{A} / \mathrm{A}-\mathrm{C} / \mathrm{A}$ & 385 (93.7) & $273(97.8)$ & 1 & & \\
\hline & & $\mathrm{C} / \mathrm{C}$ & $26(6.3)$ & $6(2.1)$ & $0.35(0.14-0.87)$ & 0.007 & 0.010 \\
\hline & Allele & A & $654(76.6)$ & 457 (81.9) & 1 & & \\
\hline & & $\mathrm{C}$ & $200(23.4)$ & $101(18.1)$ & $0.72(0.55-0.94)$ & 0.016 & 0.016 \\
\hline
\end{tabular}

To counteract the problem of multiple comparison, p-values were adjusted using false discovery rate (FDR) test. Adjusted p-value means the p-value after adjustment for FDR test. A p-value lowering 0.05 was considered statistically significant. IFI16: IFN- $\gamma$-inducible protein 16, Con: control, SCZ: schizophrenia, OR: odds ratios, CI: confidence intervals, SNP: single nucleotide polymorphism

subjects (23.4\%).

We also analyzed associations between SNPs of IFI16 and clinical phenotypes such as delusion and hallucination. However, we could not find any significant association.

Associations of haplotypes consisting of rs1465175, rs3754464 and rs1417806 with schizophrenia were assessed. Among the haplotypes consisting of three SNPs, the GAA, GGA, and TAC haplotypes were the common haplotypes showing the frequencies $\geq 0.05$ in our studied population. The frequencies of the GAA, GGA, and TAC haplotypes were $0.58,0.19$, and 0.17 , respectively.

Haplotype analysis revealed that the GGA haplotype was associated with schizophrenia $(\mathrm{p}=0.018, \mathrm{OR}=1.42,95 \% \mathrm{CI}=$
1.06-1.90) (Table 3). The frequency of the GGA haplotype was higher in schizophrenia patients $(0.23)$ than in control subjects $(0.16)$. This result indicated that the GGA haplotype contributed to an increased risk of schizophrenia.

Because rs1465175, rs3754464 and rs1417806 were located in the putative promoter region of IFI16, those could affect the promoter activity of IFI16, altering its transcription level. We measured the effects of three common haplotypes (the GAA, GGA, and TAC haplotypes) on the promoter activity of IFI16 through luciferase reporter assay. As shown in Figure 1, the promoter activity of IFI16 was enhanced in the GGA haplotype more than 3-fold, compare to the GAA haplotype; whereas it in the TAC haplotype was attenuated approximately 2 -fold. 
Table 3. Analysis of haplotypes consisting of IFI16 polymorphisms in schizophrenia patients and control subjects

\begin{tabular}{|c|c|c|c|c|c|c|}
\hline \multicolumn{3}{|c|}{ Haplotype } & \multicolumn{2}{|c|}{ Frequency } & \multirow{2}{*}{ OR $(95 \%$ CI $)$} & \multirow{2}{*}{ p-value } \\
\hline rs1465175 & rs3754464 & rs1417806 & Control & Schizophrenia & & \\
\hline G & A & A & 0.584 & 0.569 & 1 & - \\
\hline G & G & A & 0.161 & 0.230 & $1.42(1.06-1.90)$ & $0.018^{*}$ \\
\hline $\mathrm{T}$ & A & $\mathrm{C}$ & 0.195 & 0.143 & $0.75(0.55-1.03)$ & 0.072 \\
\hline G & A & $\mathrm{C}$ & 0.024 & 0.030 & $1.17(0.58-2.35)$ & 0.67 \\
\hline $\mathrm{T}$ & A & $\mathrm{A}$ & 0.021 & 0.021 & $0.94(0.42-2.10)$ & 0.88 \\
\hline G & G & $\mathrm{C}$ & 0.016 & 0.007 & $0.55(0.15-2.00)$ & 0.36 \\
\hline
\end{tabular}

*statistically significant values $(\mathrm{p}<0.05)$. IFI16: IFN- $\gamma$-inducible protein 16 , OR: odds ratios, CI: confidence intervals

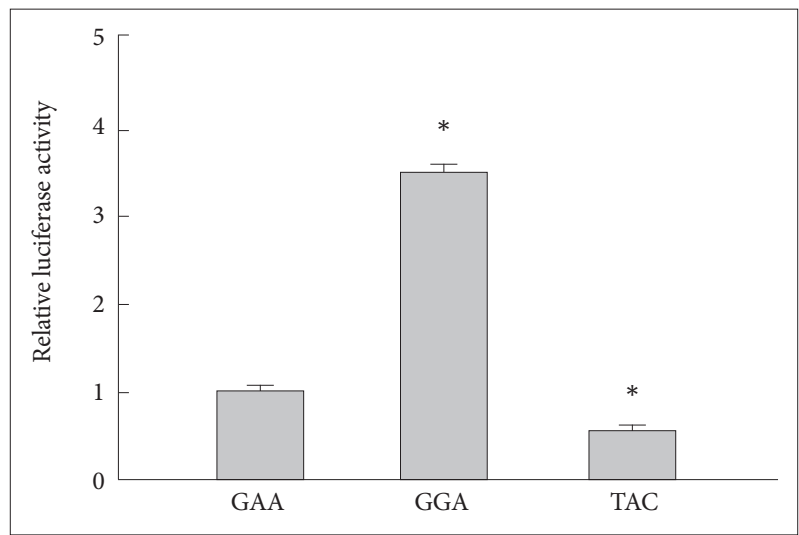

Figure 1. Effect of the haplotypes of IFI16 on the promoter activity. Luciferase activities of the haplotypes of IFI16 are presented relative to those of reference haplotype, the GAA haplotype. Data represent the mean of three individual experiments performed in triplicate ( $\mathrm{N}=9$ for each haplotype). ${ }^{*} \mathrm{p}<0.01$ compare with relative luciferase activity of the GAA haplotype. IFI16: IFN- $\gamma$-inducible protein 16.

\section{DISCUSSION}

In our study, we found significant associations of IFI16 promoter SNPs with schizophrenia in a Korean population. The T allele of rs1465175 and the $C$ allele of rs1417806 were associated with a decreased risk of schizophrenia, whereas the $G$ allele of rs3754464 was associated with the increase risk. In haplotype analysis, the GGA haplotype consisting of rs1465175, rs3754464, and rs1417806 was related to schizophrenia. The frequency of the GGA haplotype was increased in patients with schizophrenia. Moreover, we found that the GGA haplotype could significantly elevate the promoter activity of IFI16.

Growing number of studies have been suggested the involvement of viral infections in the pathophysiology of schizophrenia. The positive correlations between schizophrenia and antibody levels against the HSV-1, cytomegalovirus (CMV), mumps virus, Toxoplasma gondi (TOX), Epstein-Barr virus (EBV) and influenza have shown. ${ }^{1,25-28}$ Several viruses were also proposed to be related to symptoms of schizophrenia. Indeed, antibody levels of HSV-1 and CMV were positively associated with cognitive impairment in schizophrenia patients. ${ }^{59-11}$ In addition, Scale for the Assessment of Negative Symptoms (SANS) scores of patients with seropositive schizophrenia on HSV-1 and CMV were significantly higher than the scores of patients with the seronegative schizophrenia. ${ }^{29}$ Furthermore, HSV-1 was suggested as a maker on the severity of schizophrenia. In schizophrenia patients with HSV-1 seropositivity, a longer duration of illness, more positive symptoms, and poorer quality of life were observed..$^{30}$

Viral infections may trigger the repeated inflammatory/immunological responses, which have been linked to the pathophysiology of schizophrenia. ${ }^{28,31,32}$ IFI16, a DNA recognizing sensor, could mediate the inflammatory responses against viral infections and would contribute to the susceptibility of schizophrenia. Indeed, in our study, we found the significant association of promoter SNPs of IFI6 with schizophrenia. The T allele of rs1465175 and the $\mathrm{C}$ allele of rs 1417806 were associated with a decreased risk of schizophrenia. A previous study investigated an association between tag SNPs of IFI16 and CD4 ${ }^{+}$T-cell counts in HIV-1 infection. ${ }^{33} \mathrm{HIV}$-1-infected individuals carrying the $\mathrm{C}$ allele of rs1417806 have higher $\mathrm{CD} 4^{+} \mathrm{T}$-cell counts at set point and a slower disease progression of HIV- $1 .{ }^{33}$ Authors suggested that the $\mathrm{C}$ allele of rs1417806 might induce a lower expression of IFI16 and thus attenuate recognizing of the incomplete HIV-1 DNA transcripts via IFI16, resulting in less CD4 ${ }^{+}$T-cell death by pyroptosis. ${ }^{33,34}$ rs1465175 and rs1417806 were in strong LD in Chinese and Japanese populations at Ensemble genome browser (https://asia.ensembl.org/index.html), as well as in our studied population $\left(\left|\mathrm{D}^{\prime}\right| \geq 0.90, r^{2} \geq 0.8\right.$ ). Thus, the $\mathrm{T}$ allele of rs 1465175 together with the $\mathrm{C}$ allele of rs1417806 may also contribute to a low expression of IFI16. Our luciferase activity assay showed that the TAC haplotype comprising of the $\mathrm{T}$ allele of rs 1465175 and the $\mathrm{C}$ allele of rs1417806 significantly reduced the promotor activity of IFI16 compared to the GAA and GGA haplotypes. Thus, the subjects with the T allele of 
rs1465175 and the C allele of rs1417806 may have a low level of IFI16 and may show relatively low immunological/inflammatory responses. Taken together, the attenuated immunological/ inflammatory responses may be involved in a decreased risk of schizophrenia.

However, in the power calculation, the values of powers were 0.675 for rs 1465175 (number of effective samples=377), and 0.622 for rs1417806 (number of effective samples=426). Additionally, in the haplotype analysis, the TAC haplotype composed of the $\mathrm{T}$ allele of rs1465175 and the $\mathrm{C}$ allele of rs1417806 did not show a significant association with schizophrenia. Nevertheless, the TAC haplotype could attenuate the promotor activity of IFI16. The lack of association may be due to the relatively small number of subjects. It would be need to be validated in further studies with larger sample sizes. In order to determine the association of IFI16 with schizophrenia, replication studies are also needed.

Interestingly, the G allele of rs3754464 of IFI16 was significantly associated with an increased risk of schizophrenia. The sample power for rs3754464 (power=0.866; number of effective samples=233) was also enough to verify its statistical significance. A previous GWAS showed an association of rs3754464 with serum IgE levels although the genome-wide significance was disappeared in meta-analysis. ${ }^{35}$ The $\mathrm{G}$ allele of rs3754464 may involve in the elevation of the immunologi$\mathrm{cal} /$ inflammatory responses. In addition, we found a significant association between the GGA haplotype consisting of the $G$ allele of rs3754464 and an increased risk of schizophrenia. The GGA haplotype could increase the promoter activity of IFI16 more than 3-fold compared to the GAA or TAC haplotypes. These results indicated that the allele or haplotype of IFI16 related to its increased level might be associated with an increased risk of schizophrenia. An increased level of IFI16 could induce the relatively excessive immunological/inflammatory responses against invasions of viruses. This may be attributed to abnormal cortical circuit and increase of the susceptibility to schizophrenia.

In conclusion, promoter SNPs of IFI6, rs1465175, rs3754464 and rs1417806 were associated with schizophrenia. In the analysis of haplotypes consisting of rs1465175, rs3754464 and rs1417806, the GAA, GGA and TAC haplotypes were observed as common haplotypes in a Korean population. Among them, the GGA haplotype showed a significant association with an increased risk of schizophrenia, and elevated the promoter activity of IFI16. These results suggested that the GGA haplotype might contribute to the susceptibility of the schizophrenia, inducing the aberrant immunological and inflammatory responses through the activation of IFI16.

\section{Supplementary Materials}

The online-only Data Supplement is available with this article at https://doi.org/10.30773/pi.2019.0175.

\section{Acknowledgments}

This work was supported by a grant from the Kyung Hee University in 2017 (KHU- 20171280). We would like to thank Dr. Dong Kee Hwang, Dr. Young Jong Kim, and Dr. Jong Woo Kim for supporting for SNP genotyping.

\section{Conflicts of Interest}

The authors have no potential conflicts of interest to disclose.

\section{Author Contributions}

Conceptualization: All authors. Data curation: Hae Jeong Park. Formal analysis: All authors. Investigation: Won Sub Kang. Methodology: All authors. Project administration: Hae Jeong Park. Resources: Hae Jeong Park. Software: All authors. Supervision: Won Sub Kang, Su Kang Kim. Validation: All authors. Visualization: All authors. Writing-original draft: Won Sub Kang, Hae Jeong Park. Writing_review \& editing: All authors.

\section{ORCID iDs}

Won Sub Kang https://orcid.org/0000-0003-0495-2861

Su Kang Kim https://orcid.org/0000-0001-6178-8514

Hae Jeong Park https://orcid.org/0000-0001-8567-3535

\section{REFERENCES}

1. Brown AS, Begg MD, Gravenstein S, Schaefer CA, Wyatt RJ, Bresnahan $M$, et al. Serologic evidence of prenatal influenza in the etiology of schizophrenia. Arch Gen Psychiatry 2004;61:774-780.

2. Ellman LM, Deicken RF, Vinogradov S, Kremen WS, Poole JH, Kern DM, et al. Structural brain alterations in schizophrenia following fetal exposure to the inflammatory cytokine interleukin-8. Schizophr Res 2010;121:46-54

3. Bechter K. Updating the mild encephalitis hypothesis of schizophrenia. Prog Neuropsychopharmacol Biol Psychiatry 2013;42:71-91.

4. Prasad KM, Eack SM, Keshavan MS, Yolken RH, Iyengar S, Nimgaonkar VL. Antiherpes virus-specific treatment and cognition in schizophrenia: a test-of-concept randomized double-blind placebo-controlled trial. Schizophr Bull 2013;39:857-866.

5. Yolken RH, Torrey EF, Lieberman JA, Yang S, Dickerson FB. Serological evidence of exposure to Herpes Simplex Virus type 1 is associated with cognitive deficits in the CATIE schizophrenia sample. Schizophr Res 2011;128:61-65.

6. McQuillan G, Kruszon-Moran D, Flagg EW, Paulose-Ram R. Prevalence of herpes simplex virus type 1 and type 2 in persons aged 14-49: United States, 2015-2016. NCHS Data Brief 2018;(304):1-8.

7. Bradshaw MJ, Venkatesan A. Herpes simplex virus-1 encephalitis in adults: athophysiology, diagnosis, and anagement. Neurotherapeutics 2016;13:493-508.

8. Steiner I, Kennedy PG, Pachner AR. The neurotropic herpes viruses: herpes simplex and varicella-zoster. Lancet Neurol 2007;6:1015-1028.

9. Dickerson FB, Boronow JJ, Stallings C, Origoni AE, Ruslanova I, Yolken RH. Association of serum antibodies to herpes simplex virus 1 with cognitive deficits in individuals with schizophrenia. Arch Gen Psychiatry 2003;60:466-472.

10. Shirts BH, Prasad KM, Pogue-Geile MF, Dickerson F, Yolken RH, Nimgaonkar VL. Antibodies to cytomegalovirus and Herpes Simplex Virus 1 associated with cognitive function in schizophrenia. Schizophr Res 2008;106:268-274.

11. Watson AM, Prasad KM, Klei L, Wood JA, Yolken RH, Gur RC, et al. Persistent infection with neurotropic herpes viruses and cognitive impairment. Psychol Med 2013;43:1023-1031. 
12. Thomas P, Bhatia T, Gauba D, Wood J, Long C, Prasad K, et al. Exposure to herpes simplex virus, type 1 and reduced cognitive function. J Psychiatr Res 2013;47:1680-1685.

13. Muller N, Weidinger E, Leitner B, Schwarz MJ. The role of inflammation in schizophrenia. Front Neurosci 2015;9:372.

14. Watkins CC, Andrews SR. Clinical studies of neuroinflammatory mechanisms in schizophrenia. Schizophr Res 2016;176:14-22.

15. Sekar A, Bialas AR, de Rivera H, Davis A, Hammond TR, Kamitaki N, et al. Schizophrenia risk from complex variation of complement component 4. Nature 2016;530:177-183.

16. Shivakumar V, Debnath M, Venugopal D, Rajasekaran A, Kalmady SV, Subbanna M, et al. Influence of correlation between HLA-G polymorphism and Interleukin-6 (IL6) gene expression on the risk of schizophrenia. Cytokine 2018;107:59-64.

17. Kang WS, Park JK, Lee SM, Kim SK, Park HJ, Kim JW. Association between genetic polymorphisms of Toll-like receptor 2 (TLR2) and schizophrenia in the Korean population. Gene 2013;526:182-186.

18. Unterholzner L. The interferon response to intracellular DNA: why so many receptors? Immunobiology 2013;218:1312-1321.

19. Schattgen SA, Fitzgerald KA. The PYHIN protein family as mediators of host defenses. Immunol Rev 2011;243:109-118.

20. Xiao TS. The nucleic acid-sensing inflammasomes. Immunol Rev 2015;265:103-111.

21. Connolly DJ, Bowie AG. The emerging role of human PYHIN proteins in innate immunity: implications for health and disease. Biochem Pharmacol 2014;92:405-414.

22. Kerur N, Veettil MV, Sharma-Walia N, Bottero V, Sadagopan S, Otageri P, et al. IFI16 acts as a nuclear pathogen sensor to induce the inflammasome in response to Kaposi Sarcoma-associated herpesvirus infection. Cell Host Microbe 2011;9:363-375.

23. Eriksson K, Svensson A, Hait AS, Schluter K, Tunback P. Cutting edge: genetic association between IFI16 single nucleotide polymorphisms and resistance to genital herpes Ccorrelates with IFI16 expression levels and HSV-2-induced IFN-beta expression. J Immunol 2017;199:2613-2617.

24. McGuffin P, Farmer A, Harvey I. A polydiagnostic application of operational criteria in studies of psychotic illness. Development and reliability of the OPCRIT system. Arch Gen Psychiatry 1991;48:764-770.
25. Dalman C, Allebeck P, Gunnell D, Harrison G, Kristensson K, Lewis $\mathrm{G}$, et al. Infections in the CNS during childhood and the risk of subsequent psychotic illness: a cohort study of more than one million Swedish subjects. Am J Psychiatry 2008;165:59-65.

26. Leweke FM, Gerth CW, Koethe D, Klosterkotter J, Ruslanova I, Krivogorsky B, et al. Antibodies to infectious agents in individuals with recent onset schizophrenia. Eur Arch Psychiatry Clin Neurosci 2004;254:4-8.

27. Niebuhr DW, Millikan AM, Cowan DN, Yolken R, Li Y, Weber NS. Selected infectious agents and risk of schizophrenia among U.S. military personnel. Am J Psychiatry 2008;165:99-106.

28. Dickerson F, Jones-Brando L, Ford G, Genovese G, Stallings C, Origoni A, et al. Schizophrenia is associated with an aberrant immune response to epstein-barr virus. Schizophr Bull 2019;45:1112-1119.

29. Bolu A, Oznur T, Tok D, Balikci A, Sener K, Celik C, et al. Seropositivity of neurotropic infectious agents in first-episode schizophrenia patients and the relationship with positive and negative symptoms. Psychiatr Danub 2016;28:132-138.

30. Breier A, Buchanan RW, D'Souza D, Nuechterlein K, Marder S, Dunn $\mathrm{W}$, et al. Herpes simplex virus 1 infection and valacyclovir treatment in schizophrenia: results from the VISTA study. Schizophr Res 2019; 206:291-299.

31. Lundberg P, Ramakrishna C, Brown J, Tyszka JM, Hamamura M, Hinton DR, et al. The immune response to herpes simplex virus type 1 infection in susceptible mice is a major cause of central nervous system pathology resulting in fatal encephalitis. J Virol 2008;82:7078-7088.

32. Marques CP, Cheeran MC, Palmquist JM, Hu S, Urban SL, Lokensgard JR. Prolonged microglial cell activation and lymphocyte infiltration following experimental herpes encephalitis. J Immunol 2008;181:64176426.

33. Booiman T, Kootstra NA. Polymorphism in IFI16 affects CD4(+) Tcell counts in HIV-1 infection. Int J Immunogenet 2014;41:518-520.

34. Doitsh G, Galloway NL, Geng X, Yang Z, Monroe KM, Zepeda O, et al. Cell death by pyroptosis drives CD4 T-cell depletion in HIV-1 infection. Nature 2014;505:509-514.

35. Yatagai Y, Sakamoto T, Masuko H, Kaneko Y, Yamada H, Iijima H, et al. Genome-wide association study for levels of total serum IgE identifies HLA-C in a Japanese population. PLoS One 2013;8:e80941. 
Supplementary Table 1. Allele frequencies of promoter polymorphisms of IFI16 in ethnic populations

\begin{tabular}{|c|c|c|c|c|c|c|}
\hline & \multicolumn{2}{|c|}{ rs1465175 } & \multicolumn{2}{|c|}{ rs3754464 } & \multicolumn{2}{|c|}{ rs1417806 } \\
\hline & $\mathrm{T}$ & G & A & G & $\mathrm{C}$ & A \\
\hline African & 0.238 & 0.762 & 0.824 & 0.176 & 0.235 & 0.765 \\
\hline East Asian & 0.136 & 0.864 & 0.721 & 0.279 & 0.157 & 0.843 \\
\hline $\mathrm{CHB}$ & 0.107 & 0.893 & 0.743 & 0.257 & 0.117 & 0.883 \\
\hline JPT & 0.245 & 0.755 & 0.76 & 0.24 & 0.26 & 0.74 \\
\hline Europe & 0.336 & 0.664 & 0.984 & 0.016 & 0.302 & 0.698 \\
\hline South Asian & 0.24 & 0.76 & 0.79 & 0.21 & 0.24 & 0.76 \\
\hline American & 0.2 & 0.8 & 0.98 & 0.02 & 0.23 & 0.77 \\
\hline
\end{tabular}

Allele frequencies of each SNP in 1000Genome project are presented (http://asia.ensembl.org). CBH: Han Chinenese in Benjing, China, JPT: Japanese in Tokyo, Japan. IFI16: IFN- $\gamma$-inducible protein 16 